\title{
As competências como um modo de pensar a educação
}

\author{
Skills as a way of thinking education
}

\author{
Adair Adams* \\ Universidade de Cruz Alta \\ Elizabeth Fontoura Dorneles** \\ Universidade de Cruz Alta \\ Sirlei Lourdes Lauxen*** \\ Universidade de Cruz Alta
}

Resumo $\mathrm{O}$ artigo trata sobre a relação entre competências e educação. Retoma aspectos históricos do uso do termo tomando como materialidade de análise a legislação educacional brasileira, a partir da LDB/1996. A perspectiva dos autores encaminha a discussão para a importância da formação por competências que não objetivem apenas capacidades para o saber fazer. Entendem a importância do modelo educacional por competências, desde que a importação do campo do trabalho traga para o da educação a integralidade: aprender a criar, a fazer e a gestar. Tomam, ainda, posição contrária à fragmentação presente na legislação analisada, o que fica evidente na descontinuidade do uso de competências em leis ou partes das leis referentes aos diferentes níveis de ensino. Defendem, assim, a educação para o ser situado em todas as dimensões do viver e conviver na sociedade contemporânea.

PALAVRAS-CHAVE: Competências; Educação; Formação docente; Legislação; Modelo.

Abstract The article discusses the relationship between skills and education. Retakes historical aspects of the use of the term taking as materiality of analysis Brazilian's educational legislation, from the LDB/1996. The perspective of the authors forwarded to discussion of the importance of education for skills that do not offer only capacity for the knowhow. It is understood the importance of the educational model for skills, since the import of the fieldwork brings to the education comprehensiveness: to learn how to create, to do and to gestate. Also Taking position against the fragmentation present in the analyzed legislation, which is evident in the discontinuance of the use of skills in laws or parts of laws relating to different levels of education. They argue, therefore, education for the being situated in all dimensions of living and coexisting in contemporary society.

KEYWORDS: Skills; Education; Teacher training; Legislation; Model. 


\section{Introdução}

Um discurso recorrente e persuasivo, presente nos diferentes espaços da sociedade brasileira atual, afirma que as pessoas precisam estar preparadas para o mundo em constante transformação. Os portadores desta "boa nova" encontram-se nos grupos ou setores de poder, determinantes da ordem societal do presente, principalmente, nos meios empresariais de finanças, de mídias e de produção de bens e serviços que tem seus argumentos reforçados por ações políticas e, também, acadêmicas, em termos de qualificação profissional. Até porque, segundo este discurso, cabe à educação a execução dessa tarefa.

Por este viés, a educação é pauta principal das discussões de governos, organismos, empresas e da sociedade como um todo. Ela é apontada como causa/solução de todas as mazelas que afligem a sociedade contemporânea. Na educação está a justificativa das mazelas da sociedade, enquanto as da educação estão justificadas nas da sociedade. O discurso circular é: a educação não muda, porque a sociedade está mal e a sociedade não muda porque a educação está mal. Assim, gira-se em torno de uma espiral mais de acusações do que de justificações, em que o pressuposto de justificação é injustificável.

A questão que orienta a argumentação deste texto, sobre a formação por competências, pode construir respostas para estas e outras indagações correlatas que são determinantes para pensar o mundo, a educação, a escola e o educador(a) que temos e queremos para o futuro. Ora, se pairam dúvidas sobre a escolha do mundo desejado, não podemos afirmar o mesmo sobre as opções identificadas, quais sejam: a manutenção do sistema atual tendo a economia de mercado como paradigma predominante; ou, a implantação de outro sistema que tenha o bem estar do ser humano como referência.

Não é o desenvolvimento de uma racionalidade técnica e instrumental que efetiva uma qualidade gestora de trabalhos, mas de trabalhadores para trabalhos já gestados por uma lógica de mercado de países desenvolvidos. Com essa diferenciação básica, a formação de educadores por competências recebe uma orientação muito distinta e variada nos diversos contextos. Assim, a base argumentativa é o ser educador que se organiza em diversos modos para sua atuação no contexto da sociedade brasileira. A formação por competências é considerada um modo de ser educador e não o ser educador um modo de ensinar por competências, em que pode ter outros modos de ensinar. Competências é uma metáfora de compreensão da docência e não a docência uma metáfora de compreensão de competências.

O artigo está organizado a partir das temáticas da educação por competência como contexto; história da formação do conceito na educação brasileira; nosso mundo vivenciado tecnicamente; limites do conceito de competências; limites da proposta de formação por competências; possibilidades de formação de educadores por competências; a eticidade do diálogo pedagógico como base de qualquer proposta educativa por competências. 


\section{Educação por competência como contexto}

Em termos de educação brasileira, as necessidades que a sociedade cria, em boa medida, vão de encontro aos desejos dos seus gestores. A sociedade é processo e resultado de uma educação, que, por ordem de necessidades e possibilidades, condiciona os rumos empreendidos no país. É por essa ordem de necessidades e possibilidades que a educação e a sociedade se transformam conjuntamente. A sociedade, porém, se transforma sem se preocupar se isso ocorre de maneira justa, transformando também a educação, sem resolver a questão de uma formação educativa de direitos iguais e liberdade para todos. Nesse sentido, Morin (2002, p. 100) interroga: "Como reformar a escola sem reformar a sociedade, mas como reformar a sociedade sem reformar a escola?".

A gestão da educação como trataremos no próximo item, tem nas competências e na sua diversidade compreensiva e interpretativa um dos seus elementos organizadores das políticas públicas. Esta decisão está justificada no contexto epocal societal brasileiro e, como interpretação sociológica manifesta uma estrutura que busca se desenvolver a partir de modelos econômicos e de gestão importados dos países desenvolvidos. Mas tal importação tem como carga apenas uma parte desses modelos, que é da produção de bens e serviços. Ao Brasil não chegaram as possibilidades de criação e gestão e entende-se que a educação por competências está condicionada à implementação desse modelo completo.

A partir disto, é possível compreender as diversas críticas à forma de pensar a educação como de cooptação ao mercado de trabalho e de uma racionalidade técnica instrumental. O Brasil optou por um modelo de desenvolvimento que cria necessidades distintas das de seus gestores. Este contexto é base para compreender a educação por competências sem uma posição prévia, simplesmente, de crítica ou aceitação. Segundo Markert (2002), esclarecer esta realidade permite debater e refletir sobre as competências não somente no trabalho, mas na vida, visto que o modelo político-econômico capitalista e globalizante "demonstra ainda uma grande incerteza sobre as suas fundamentações teórico-metodológicas e prático-pedagógicas, o que repercute diretamente sobre o entendimento de que seus objetivos venham a ser emancipatórios ou somente instrumentais".

A escola pode se organizar em torno das necessidades e possibilidades da sociedade no presente, sejam elas de transformação social e cultural, luta (consciência crítica) ou de qualificação profissional e, dessa forma, poderia tornar-se emancipatória. O modelo de gestão de desenvolvimento que a globalização procura efetivar em todo o mundo ocidental, com diferentes modos de efetivação, segundo Novaes (2009), faz do nosso mundo vivido um mundo técnico e instrumental. Este modo de ser na techne se manifesta de diversas formas. A atualidade, resultante de um passado vivo que emerge mais acentuadamente das duas revoluções industriais, faz da técnica o modo de organização do mundo. Os países desenvolvidos procuram dominar a técnica e exportá-la para todo o mundo como instrumentos tecnológicos utilizados no cotidiano da organização societal. Por outro lado, Santos (2006) nos aponta para o fato de que ao Norte, aos países desenvolvidos, exportadores de tecnologias, não é produtiva a preocupação dos menos desenvolvidos, ou do Sul, com o passado. Para os primeiros 
somente o presente importa. A busca das raízes, da dualidade que as narrativas trazem para a constituição de identidades, deve ser silenciada. A negação do passado funciona mantendo "cada um no seu lugar". Enquanto que o conhecimento das raízes tem que ser feito para a real emancipação, pois delas podem emergir muitas opções de presente e de futuro.

Nesta perspectiva, a educação por competências tem como horizonte a qualidade ou a qualificação para esse modo técnico de organização das sociedades. No Brasil, hoje, espalham-se os Centros Tecnológicos, pois o modelo de desenvolvimento adotado vem provocando a inserção na legislação educacional brasileira, desde a Reforma Capanema, período Vargas, até a atualidade, de dispositivos legais que incentivam e regulamentam a educação tecnológica, ou numa linguagem mais atual, Educação para o Trabalho ou, ainda, Educação Politécnica. A qual não necessita do modelo completo de formação por competências: criação e gestão podem ficar fora. Para o modelo de desenvolvimento brasileiro atual, Centros Humanistas, talvez, seriam um atraso e até mesmo um empecilho. Basta ver como as universidades estão fechando os departamentos de ciências humanas.

Nesse jogo de necessidades, a escola tem como papel central compreender quem as cria, pois ela mesma pode se tornar desnecessária para a sociedade. Esta situação tem como pressuposto um mundo vivido "em que existe cada vez mais informação e cada vez menos sentido" (BAUDRILLARD, 1978, p. 26). A informação escapou da gestão da escola. "Estamos saindo da civilização reta do estilo para entrar na dos teclados, planária, volumosa e descentrada. Isso nos mudará, corpos e almas, e isso transformará o tempo" (SERRES, 1998, 12).

\section{História da formação do conceito}

A formação por competências, antes de ser uma proposta para a educação, é um modo de organizar-se no todo da sociedade. As competências estão ligadas, sobretudo, à organização da sociedade em torno do desenvolvimento tecnológico, ocorrido em escala determinante desde as revoluções industriais. As tecnologias não se tornaram apenas formas de qualificar o trabalho, mas o centro das pesquisas e do desenvolvimento econômico, bem como o modo de o homem se organizar e viver.

A formação por competências entrou de modo decisivo na educação brasileira a partir das décadas de 80 e 90 . Nesse período, ela chega como uma maneira de formação já efetivada nos países de primeiro mundo, sobretudo na Inglaterra. O Brasil importa esse modo de pensar em termos de construção das suas políticas educacionais. É justamente nesse contexto que iremos nos deter, pois, a partir dos usos e empregos das competências, trabalharemos sua complexidade e multiplicidade conceitual.

No caso do Brasil, segundo Ferreti (1997), o processo que culminou com a aprovação da LDB, apesar da aparente abertura para intervenções da sociedade, foi pouco democrático. Para Frigotto (1995), com a LDB e posteriormente com o Plano Nacional de Educação instaurou-se no País "uma reforma educativa autoritária e em consonância com o ajuste neoliberal tanto no plano institucional quanto no plano da 
concepção educativa”. Segundo Kuenzer (1997), a Lei não atendeu às propostas das organizações acadêmicas, entidades de classes e movimentos sociais, que teriam sido "ludibriados" por uma estratégia que fez com que os mesmos se concentrassem nas tentativas de discussão ou rejeição da LDB, enquanto as verdadeiras reformas foram sendo feitas aos poucos, por meio de propostas legais específicas para cada parte da educação nacional, perdendo dessa forma a visão da totalidade e, com isso, a capacidade para uma intervenção mais orgânica, e por isso mais competente.

O fato de a LDB ser um documento complexo e até mesmo paradoxal em relação à questão abordada, não pode, sob hipótese alguma, servir de argumento para o imobilismo, mas sim, ao desafio para produção de ideias e de práticas educacionais nas quais as pessoas, que labutam na educação, acreditem. O cuidado, nesta perspectiva, é o de garantir que a individualidade e a autonomia de pessoas, instituições e governos se coadunem em projetos cujos resultados promovam o bem comum e o bem estar social à coletividade.

Partimos, então, de um discurso presente na sociedade, de modo geral, e nas escolas, de modo específico, que considera a "competência" como condição para o exercício de qualquer profissão. No caso do exercício da docência, nos parece que o termo competência divide espaço com os termos conhecimento e saberes. Puentes, Aquino \& Neto (2009), que analisaram as diferentes classificações e tipologias sobre os conhecimentos, saberes e competências necessários ao exercício da docência identificaram os principais autores que utilizam estes termos. Entre eles, competências são designadas como: Shulman e García utilizam a expressão "conhecimentos necessários à docência"; Freire, Pimenta, Gauthier, Tardif e Cunha utilizam a expressão "saberes necessários à docência”; já Masetto, Braslavsky, Perrenoud e Zabalza utilizam a expressão "competências necessárias à docência".

Dentro da LDB, o desenvolvimento de competências não é previsto; apenas no artigo que trata da formação dos profissionais da educação, os termos conhecimento e competência aparecem juntos; diz o item I do Art. 61: "a presença de sólida formação básica, que propicie o conhecimento dos fundamentos científicos e sociais de suas competências de trabalho". Ocorre que, em função da estrutura e funcionamento do Conselho Nacional de Educação (CNE), a elaboração dos pareceres e das diretrizes curriculares nacionais foi realizada por diferentes grupos de pessoas, logo, com diversas perspectivas e visões sobre o papel da educação, da escola, do ensino; talvez por isso o termo competência não apareça em todas as diretrizes.

Por outro lado, a ênfase no uso do termo competência em diretrizes como do Ensino Médio, Educação Profissional de Nível Técnico e, Formação de Professores da Educação Básica, em Curso Superior, Curso de Licenciatura de Graduação Plena corroboram com a reforma educacional foi executada em cada nível ou modalidade de ensino de forma isolada, mas com o objetivo de constituir uma reforma ampla, única e coletiva. Evidentemente, uma reforma com tamanhas contradições encontraria - como tem encontrado - inúmeras dificuldades de planejamento, execução e avaliação. 
No entanto, pela propaganda oficial, a ideia de que se cada nível ou modalidade de ensino cumprisse as suas diretrizes teríamos um projeto de educação nacional foi disseminada na sociedade brasileira e nas instituições educativas. Esse engodo, não acontece apenas a partir dessa LDB - como já apontamos, é anterior e histórico no País - no entanto, se acentua a partir da nova lei; pois, por paradoxal que possa parecer, é justamente ao tentar garantir às pessoas o direito e o acesso à escola e a educação, que o legislador promove, na maioria das vezes, uma espécie de apartheid educacional, como se cada nível ou modalidade de ensino se constituísse de forma individual no sistema educacional. Senão, vejamos a utilização do termo competências nas Diretrizes Nacionais Gerais para a Educação Básica, Resolução CNE/CEB no 4/2010, aprovada em 13 de julho de 2010:

a) para a Educação Infantil, observa-se que o termo competência não aparece e a resolução determina que as Propostas Pedagógicas das Instituições de Educação Infantil, devem contribuir com o "provimento de conteúdos básicos para a constituição de conhecimentos e valores."

b) para o Ensino Fundamental, o termo competência não aparece em momento algum; pela resolução, os alunos ao aprenderem os conhecimentos e valores estarão constituindo suas identidades como cidadãos.

c) para o Ensino Médio, o termo conhecimento praticamente desaparece e entram em cena, primeiro, uma conceituação nos termos das competências e, em seguida, habilidades, como se, ensino fundamental e ensino médio, não fizessem parte do mesmo nível de ensino, no caso, da Educação Básica;

A argumentação referente às modalidades da educação básica coloca-se na seguinte perspectiva:

d) para Escolas Indígenas, os termos conhecimentos e competências aparecem em dois artigos; quando trata da organização da escola indígena afirma que a mesma deve levar em conta "suas formas de produção de conhecimento, processos próprios e métodos de ensino-aprendizagem";

e) para a Educação Profissional, sobretudo as diversas modalidades técnicas são as que mais incorporaram o termo competência, a ponto de o termo conhecimento aparecer uma única vez na resolução; aponta ainda para a possibilidade de o Ministério da Educação em conjunto com demais órgãos federais das áreas e Conselho Nacional de Educação, organizar um sistema nacional de certificação profissional baseado em competências;

f) para a Educação de Jovens e Adultos, no ensino fundamental e ensino médio, são constituídas a partir das diretrizes do Ensino Fundamental e do Ensino Médio, respectivamente, e com as diferenças mencionadas anteriormente, ou seja: para o ensino fundamental conhecimentos e para o ensino médio competências;

g) para a Educação Especial, são ampliados a capacidades a serem desenvolvidas, além de valores, conhecimentos, habilidades e competências é acrescentado atitudes. 
h) para Formação de Professores da Educação Básica, em Curso Superior, Curso de Licenciatura de Graduação Plena se afirma que deve ser observada "a competência como concepção nuclear na orientação" dos cursos de formação de professores.

i) para Formação de Docentes da Educação Infantil e dos anos iniciais do Ensino Fundamental, em nível médio, na modalidade Normal, é interessante observar o surgimento de uma contradição, pois enquanto nas Diretrizes para o Ensino Fundamental e Educação Infantil o termo competência não aparece, nesta que trata da formação de professores naquelas modalidades o termo competência, como adjetivo desejado ao professor, começa a ser adotado.

Pela leitura da diretriz, os conhecimentos podem ser entendidos como condição para a constituição de competências, logo a validade dos conhecimentos do professor está intimamente relacionada à utilização ou transformação do mesmo em competências, ou seja, o conhecimento como insumo; o conhecimento como algo aplicável e mensurável.

Nessa perspectiva, o exercício da docência e, por consequência, os profissionais podem e devem ser quantificados, medidos, comparados e assim conceituados como eficientes, eficazes e competentes; ou, o oposto, como ineficientes, ineficazes e ... incompetentes. Teríamos então a transposição do modelo de prática profissional adotado na produção industrial de peças, carros, galinhas entre outros, para a produção nas escolas, em escala industrial, de pessoas.

Connell (2012, p. 7) discute a formação de educadores por competências e afirma que em tal modelo de formação, gestado dentro de uma concepção neoliberal do ensino, "não há necessidade alguma de conceber a educação como uma disciplina intelectual". Como "o neoliberalismo desconfia dos educadores", todo o contexto educacional - escola, educador e aluno - e as relações estabelecidas entre os mesmos passam a ser necessariamente medidos, quantificados, avaliados e "auditoráveis". Talvez por isso, como afirmamos anteriormente, as Diretrizes para a Educação Profissional (2012) e para a Formação de Professores (2002) apresentem tantas listas de competências e habilidades a serem atingidas. Como são também listas de desempenho passíveis de avaliação "transformar-se na própria razão de ser de um programa de formação de educadores”.

\section{Limites do conceito e da proposta de competências}

Há uma polissemia significativa para o conceito de competências. Nem é preciso pensar isso em termos de diversidade de documentos e regulamentações como vimos em relação à $\mathrm{LDB}$ e às Diretrizes. Compreensível tal polissemia, uma vez que a noção de competências se origina no modelo toytista que organiza a produção industrial a partir do final do Século XX, é adotada como orientadora das ações para formação de trabalhadores pela Organização Internacional do Trabalho - OIT e chega ao Brasil, formando parceria para a disseminação com o Ministério do Trabalho e Emprego - MTE e migra logo depois para a Educação. Algumas definições de 
competências delimitam seu objetivo e prática pedagógica a uma situação específica da sociedade, que é o mundo do trabalho e da economia.

Em qualquer área de atuação da sociedade é requerida competência de ação no sentido de fazer com qualidade. Assim, na educação, o educador precisa ser competente com aquilo que ele faz, mesmo não sendo um dos trabalhos de demanda da estrutura da sociedade de economia de mercado. Não há uma ligação direta entre ser um educador de qualidade e responder com as necessidades profissionais qualificadas dos seus alunos para atuar na sociedade.

Não queremos defender a formação de educadores por competências a partir da condição de sua polissemia no sentido de nos isentarmos de críticas às suas propostas educativas. Colocamos a impossibilidade de jogar tudo fora sem ao menos fazer uma diferenciação compreensiva, que permita entrever os limites, primeiro pela confusão conceitual e, então, pelas propostas e racionalidades implicadas em cada uma.

Compreendemos que, a partir do contexto societal e das definições da proposta de educação por competências, se constituem as possibilidades de apontar seus limites. Dessa forma, a crítica corrente de que as competências pressupõem uma racionalidade técnica é viável quando for dirigida para a conceituação, que delimita as competências a efetivação desta racionalidade. Por esta razão, queremos apontar alguns limites seguindo suas próprias definições.

Algumas definições de competências delimitam seu objetivo e prática pedagógica a uma situação específica da sociedade, que é o mundo do trabalho e da economia. Segundo Ferreti (1997, p. 79), corre-se o risco de que a educação fique "a reboque dos interesses produtivos, ainda que os discursos ressaltem seus aspectos formativos gerais".

A interpretação que Machado (1998) é de que estamos diante de um processo de institucionalização de uma lógica das competências no Brasil. Trata-se de uma lógica social que está sendo produzida. $\mathrm{O}$ autor constata que a institucionalização da noção de competências tem como resultado uma crescente homogeneização ideológica determinada pela economia de mercado.

A proposta das competências está direcionada para o momento atual da sociedade como economia de mercado. A questão central criticada por Machado (2002) é que essa situação está determinando todo um sistema de ordenamento da sociedade que ultrapassa a questão da qualificação da formação brasileira, em que a proposta das competências tem sido a vigente. Desta maneira, a proposta está corroborando a efetivação de um modelo de sociedade que se manifesta como falido devido às mazelas sociais que tem criado, às falências propositais de países, à exclusão de diversos setores humanos e a um ritmo de vida que oprime a condição humana de ser e viver.

A produção de uma lógica social do uso da noção de competências é constatável também por sua generalização a outras esferas de formação que não a profissional. Questionamos as possibilidades de uma proposta única de competências para todos os setores da educação. Esta falta de abertura para dimensões outras, coloca-se como um 
elemento que contradiz a sua proposta educativa. Ser competente, como uma qualificação, não pode estar circunscrito a um modo de organização da sociedade. Em todos os setores da sociedade e da educação, é preciso qualidade, sobretudo uma qualidade de vida para os envolvidos. A qualificação já não pode ter como horizonte de medida a economia de mercado, nem seus índices de desenvolvimento.

\section{Possibilidades da educação por competências}

Esta pluralidade conceitual precisa ser entendida para que dela se possa extrair e pensar uma proposta pedagógica, para além dos limites apontados. $\mathrm{Na}$ sociedade atual, a experiência nos mostra que a competência profissional faz diferença. $\mathrm{O}$ educador é um sujeito da ação docente que faz, age, está para além do conhecimento da matéria/conteúdo, sendo reconhecido como ator e não simples técnico, no entanto, é "necessário levar em conta a subjetividade dos atores em atividade, isto é, a subjetividade dos próprios professores" (TARDIF, 2005, p. 230). É a partir do consenso formado pelo coletivo, no exercício constante de fala e de escuta entre pares que acontecerá a unidade, sem, contudo, reduzi-la à uniformidade, mas uma unidade no sentido de reforçar as diferenças surgidas na ação desse coletivo.

Para Perrenoud (2000), o exercício da docência como trabalho humanista está marcado pela exigência de saber os seus limites. Não há como a escola ser o único lugar de melhoramento do mundo através da qualificação dos seus indivíduos. Não cabe à escola ter um sentimento de culpa pela impossibilidade de transformação das peripécias que o mundo tem gerado. Mas isso não exime a escola da responsabilidade de ser mais ágil, mais perspicaz no seu processo e na sua caminhada de educação, como meio de formação da cultura e do melhoramento da sociedade, sobretudo, da condição de vida de todas as pessoas.

Nesta perspectiva, a proposta por competência, numa dimensão da educação, concretiza-se no ensino profissionalizante. Para essa dimensão da educação, a proposta por competências tem como pressuposto central a construção de aprendizagem interativa entre a sala de aula e o seu mundo, efetivando uma prática socioconstrutivista. O conhecimento é interdisciplinar e contextualizado, privilegiando a construção de sentido, que liga a sala de aula com seu mundo prático.

Para que essa forma de conhecimento torne-se possível, a proposta por competências está focada em conteúdos que expressam a interatividade entre todo o meio do qual o aluno faz parte. Isso requer um currículo dinâmico e organizado em torno do mundo prático, que segue uma estrutura de conhecimentos aberta à necessidade de saber orientar e aos problemas gerados no dia-a-dia dos alunos. Toda a atividade escolar está centrada na aprendizagem, que permite a criação de possibilidades de viver no âmbito da sociedade em que se está inserido. Segundo Perrenoud (2000, p. 15), a competência que se produz no todo da relação de aprendizagem é a "capacidade de mobilizar diversos recursos cognitivos para enfrentar um tipo de situações".

A educação não se compreende a partir de uma representação ordenada, que progride de forma linear segundo princípios pedagógicos estabelecidos apenas 
verticalmente, que acabam desvelando uma perspectiva desanimadora para os professores se não for devidamente compreendida e assumida por todos. É a perspectiva de uma educação que está permeada de complexidade, de antagonismos, que interpreta a educação como "uma profissão impossível, porque é uma profissão complexa, que obriga a enfrentar contradições irredutíveis, tanto no espírito do ator quanto nas relações sociais" (PERRENOUD, 2001, p. 22).

A educação por competências propõe uma prática que é muito mais que uma tarefa complicada, que poderia ser enquadrada na metodologia corrente, oriunda da modernidade, de uma fragmentação de conhecimentos, por uma decomposição que poderia solucionar os problemas particulares e peculiares que se apresentam e afetam a educação como um todo.

\section{Considerações finais}

Partimos do pressuposto de que é possível um critério de eticidade que permita estabelecer as competências formativas do educador. Essa ideia decorre da constatação de que uma postura ocidental de se situar frente ao mundo e de compreendê-lo constitui a essência de nossa tradição filosófica, e está implícita no nosso comportamento e nas nossas atitudes diante dos outros e diante da vida. Enquanto não forem devidamente explicitados e criticados, esses pressupostos permanecerão subjacentes em nossas posturas, impedindo qualquer mudança mais profunda em nossas práticas. Esta maneira de encarar a realidade vai exigir muito mais do que uma simples proposta, vai exigir uma postura ética do educador, pesquisador, ou cientista social.

Em contraponto à categoria da identidade, Bakhtin propõe a categoria da alteridade. Aqui, o respeito ao outro ocorre mediante o reconhecimento de sua alteridade e ocorre pelo dialogismo, que pode ser considerado um conceito de ética - uma ética da alteridade. Assim, antes de uma competência para o mundo do trabalho, para uma profissionalização qualquer, é preciso que o ser humano seja capaz de conviver politicamente uns com outros. Essa é a tarefa básica da educação, de conduzir as novas gerações ao mundo público da política antes de conduzir para o mundo do trabalho.

A alteridade define o ser humano, pois o outro é imprescindível para sua concepção. O dialogismo, em Bakhtin, assinala a presença do outro na constituição dos sentidos das palavras, daquelas que tecem a realidade do existir humano, que compõem o pensamento do homem no coletivo.

Nessa perspectiva pedagógica, o compromisso com as novas gerações se coloca em termos de responsabilidade. Segundo Marques, "[...] necessita fundar-se a educação no mundo dos homens que ouvem uns aos outros, postos à escuta das vozes que o interpelam" (1990, p. 163). Esta pedagogia reconhece a interpelação como ato de fala por excelência.

Sendo a ação educativa escolar "um fazer intencional" (BOUFLEUER, 1997, p. 10), a exigência de uma postura ética do educador na mediação, que estabelece com seus alunos deve ser assumida como competência primeira desse educador, a competência do educador seria a capacidade de reconhecer quais são "as vozes que o interpelam". 
Podemos dizer que a epistemologia da prática (THERRIEN, 2010, p. 307) expressa nas Diretrizes Curriculares Nacionais para a Formação de Professores da Educação Básica (Resolução CNE/CP 1, de 18 de fevereiro de 2002), apontada pelo próprio documento como fundante da competência para o ensino, pode se tornar uma mera convenção se não for conduzida por princípios éticos, entendendo a prática, desde o início como escuta da voz do outro, como respeito ao outro na sua alteridade, condição primeira do verdadeiro diálogo (BAKHTIN, 1988). É nessa prática, no mundo da vida da escola, que o educador em formação vai buscar subsídios para a fundamentação teórica das discussões a nível acadêmico. É nesse diálogo que se vão constituindo as competências, desfazendo-se a polêmica dicotomia entre teoria e prática. Também nesse diálogo, que subentende a escuta, o educador em formação elencará quais saberes disciplinares e curriculares serão significativos para a sua profissão e que servirão de referência para as pesquisas daí decorrentes.

\section{Referências}

BAKHTIN, Mikhail. Questões de literatura e de estética: a teoria do romance. São Paulo: Hucitec/UNESP, 1988.

BAUMAN, Zigmunt. Vida Líquida. São Paulo: Zahar, 2007.

BAUDRILHARD, Jean. Cultura y simulacro. Barcelona: Ed. Kairós, 1978.

BOUFLEUER, José Pedro. Pedagogia da Ação Comunicativa. Ijuí: UNIJUÍ, 1997.

BRASIL. Lei no 9.394, de 20 de dezembro de 1996. Lei de Diretrizes e Bases da Educação Nacional. Diário Oficial da União, Brasília, DF, 24 dez. 1996. Seção 1, p. 27-833. Disponível em: <http://www.planalto.gov.br/ccivil_03/Leis/L9394.htm>. Acesso em: 15 mar. 2016.

BRASIL. Resolução No 4, de 13 de Julho de 2010b. Diretrizes Curriculares Nacionais Gerais para a Educação Básica. Diário Oficial da União. Brasilia, DF, 09 de Julho de 2010. Seção 1, p. 824. Disponível em: 〈http://portal.mec.gov.br/dmdocuments/rceb004_10.pdf〉. Acesso em: 23 abr. 2016

BRASIL. Resolução No 6 de 20 de setembro de 2012. Diretrizes Curriculares Nacionais para a educação Profissional Técnica de Nível Médio. Diário Oficial da União. Brasília, DF, 04 de setembro de 2012. Seção 1, p. 98.

BRASIL. Resolução do CNE/CP No 1 de 18 de fevereiro de 2002. Diretrizes Curriculares Nacionais para a Formação de Professores da Educação Básica, em nível superior, curso de licenciatura, de graduação plena. Diário Oficial da União. Brasília, DF, 09 de abril de 2002. Seção 1, p. 31.

CONNELL, Raewyn. A iminente revolução na teoria social. RBCS, vol. 27, n 80, out., 2012.

FERRETTI, C.J. Formação profissional e reforma do Ensino Técnico no Brasil: Anos 90. Educação \& Sociedade no 59. Campinas: Cedes, ano XVIII, ago. 1997.

FRIGOTTO, G. A interdisciplinaridade como necessidade e como problema nas ciências sociais. Petrópolis, RJ: Vozes, 1995.

KUENZER, A. Z. Ensino médio e profissional: as políticas do Estado neoliberal. São Paulo: Cortez, 1997.

MACHADO, Lucília. Educação básica, empregabilidade e competência. Revista Trabalho e Educação, n.3, p.15-31, jan./jul. 1998.

MARKET, W. Trabalho e comunicação: reflexões sobre um conceito dialético de competência. 
Revista Educação \& Sociedade, ano XXIII, n. 79, ago, 2002.

MARQUES, Mário Osório. Pedagogia: a ciência do educador. Ijuí: UNIJUÍ, 1990.

MORIN, Edgar. A cabeça bem-feita: repensar a reforma, reformar o pensamento. Rio de Janeiro: Bertrand Brasil, 2002.

NOVAES, Adauto. Entre dois mundos. In: NOVAES, Adauto. A Condição Humana. São Paulo: Agir, 2009.

PERRENOUD, Philippe. 10 novas competências para ensinar. Porto Alegre: Artes Médicas Sul, 2000. 2001.

Dez novas competências para uma nova profissão. Revista Pedagógica, n. 17, maio-jul,

PUENTES, Roberto Valdés; AQUINO, Orlando Fernández; NETO, Armindo. Profissionalização dos professores: conhecimentos, saberes e competências necessários à docência. Revista Educar, Curitiba, n. 34, 2009.

SANTOS, Boaventura de Sousa. A gramática do tempo. Para uma nova cultura política. São Paulo: Editora Cortez, 2006.

SERRES, Michel. O terceiro instruído. Lisboa: Instituto Piaget, 1998.

TARDIF, Maurice; LESSARD, Claude. O trabalho docente: elementos para uma teoria da docência como profissão de interações humanas. Petrópolis: Vozes, 2005.

THERRIEN, Jacques. Da Epistemologia da Prática à Gestão dos saberes no Trabalho Docente: Convergências e Tensões nas Pesquisas. In: Coleção Didática e Prática de Ensino. Belo Horizonte: Autêntica, 2010.

* Professor doutor da Universidade de Cruz Alta, Cruz Alta, Rio Grande do Sul, Brasil.

** Professora doutora da Universidade de Cruz Alta, Cruz Alta, Rio Grande do Sul, Brasil.

*** Professora doutora da Universidade de Cruz Alta, Cruz Alta, Rio Grande do Sul, Brasil.

\section{Correspondência}

Elizabeth Fontoura Dorneles - Universidade de Cruz Alta, Departamento de Artes Comunicação e Letras, Curso de Letras. Campus Universitário Dr. Ulysses Guimarães. Rodovia Municipal Jacob Della Mea Km 5,6. Parada Benito. CEP: 98020-290. Cruz Alta, Rio Grande do Sul, Brasil.

E-mail: adairadas@gmail.com - edorneles@unicruz.edu.br - slauxen@unicruz.edu.br

Recebido em 06 de junho de 2016

Aprovado em 12 de maio de 2017 